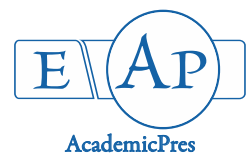

\title{
Hepatic Histomorphological Changes and Oxidative Stress Profile of Clarias gariepinus (Burchell, 1822) Juveniles Fed with Sodium Propanoate-Preserved Diets
}

\author{
Patrick E. ABA ${ }^{1,3 *}$, Ifeanyi E. UZOCHUKWU ${ }^{2}$, Nelson I. OSSAI ${ }^{3}$, \\ Ifeanyi G. EKE ${ }^{1}$ \\ ${ }^{1}$ University of Nigeria, Department of Veterinary Physiology and Pharmacology, Nsukka, Nigeria; \\ ${ }^{2}$ University of Nigeria, Department of Animal science, Nsukka, Nigeria \\ ${ }^{3}$ University of Nigeria, Department of Zoology and Environmental Biology, Nsukka, Nigeria; \\ Patrick.aba@unn.edu.ng ('corresponding author)
}

\begin{abstract}
Sodium propanoate is in the list of approved feed preservatives. However, there is dearth of information on its biological effects on the C. gariepinus. The present study investigated the effect of sodium propanoate-preserved feed on the hepatic histomorphometric changes, oxidative stress and inflammatory parameters of C. gariepinus juveniles. One hundred juveniles of mixed sexes, assigned into 5 groups of 20 fish per group, with each group consisting of 2 replicates of 10 fish, were used for the investigation. Group A juveniles were fed basal diet, while groups B-E received basal diet incorporated with sodium propanoate at the rate of $25,50,75$ and $100 \mathrm{~g} / 15 \mathrm{~kg}$ of feed respectively. Treatments were done two times daily for 8 weeks. Samples (sera and liver) were collected on the last day for evaluation of a few biochemical parameters (malondialdehyde values, catalase activity, C-reactive protein levels) and histomorphometric alterations in the liver. Results indicated that fish in groups D and E had higher catalase activities, lower serum levels of C-reactive proteins and an intact hepatic histomorphormetry when compared with the control group. There was no significant difference in the plasma malondialdehyde values in all the groups. It was concluded that preservation of fish feed with sodium propanoates improved antioxidant status of C. gariepinus and protected liver histology.
\end{abstract}

Keywords: Clarias gariepinus; C-reactive protein; hepatic histomorphometry; oxidative stress markers; sodium propanoate

\section{Introduction}

Sodium propanoate or sodium propionate is a white deliquescent crystalline solid with the chemical formula of $\mathrm{Na}\left(\mathrm{C}_{2} \mathrm{H}_{5} \mathrm{COO}\right)$. It can be obtained following a reaction between propionic acid and sodium carbonate. Sodium propanoate finds application in food industry as food additive and as a mold inhibitor in bakery (Brock and Buckel, 2004). It is an approved food preservative. The use of non-antibiotic promoters such as sodium propanoate has been widely advocated for owing to deleterious effects associated with the use of antibiotics in aquaculture (da Silva et al., 2014).

Preservation of fish feed is very important not only for extending the shelf life, but the process may also affect the health status of the fish. Evaluation of blood biochemistry parameters is vital in ascertaining the effects of xenobiotics, monitoring of therapy and for assessing the health status of living organisms (Okorie-kanu and Unkalamba, 2016).

It is also noteworthy that stressful conditions in aquaculture are a major factor militating against large scale productions in fish industry (Subramanian et al., 2013). It is therefore important to monitor oxidative stress indicators such as malondialdehyde and stabilize them for optimum operation of aquaculture.

Malondialdehyde is a low molecular weight aldehyde with three carbon molecules. It is a lipid peroxidation product which is very reliable in assessing oxidative stress (Grotto et al., 2009). It indicates the level of lipid peroxidation by reactive oxygen species (ROS). Consequent upon metabolic processes, different cells in the body of living organisms constantly generate ROS, which will eventually peroxidize lipids (Urso and Clarkson, 2003). 
Catalase is a tetrameric antioxidant enzyme which is involved in conversion of harmful hydrogen peroxide to innocuous water and molecular oxygen (Chelikaniet al., 2004). Its assessment is crucial as it indicates the antioxidant status of an organism and in turn, the ability of such organism to handle oxidative stress. Catalase is commonly seen in all the cells that are exposed to oxygen (Aba and Okenwani, 2015).

C-reactive protein is an acute phase protein which serves as a reliable marker of inflammation (Young et al., 1999). Its synthesis is in the liver. The serum level of C-reactive protein rapidly increases during inflammation because of its role in opsonization (Ballou and Kushner, 1992). C-reactive protein will bind to a substance known as phosphocholine which is expressed by damaged cells. It also binds to peptosaccharrides and polysaccharides expressed by bacteria and fungi (Ballou and Kushner, 1992).

Liver is a vital organ in the body, being involved in a greater percentage of metabolizing foreign materials and drugs. Histomorphometric assessment of the liver always reveals its health status (Aba and Asuzu, 2015). There is dearth of information on the effect of sodium propanoate on some oxidative stress parameters and liver histology of $C$. gariepinus.

The present study therefore was carried out to investigate the effects of preserving fish feed with sodium propanoate on some oxidative stress indicator parameters, antioxidants profile, inflammatory status and hepatic histomorphormetry of Clarias gariepinus juveniles.

\section{Materials and Methods}

\section{Experimentalfish}

One hundred Clarias gariepinus juveniles of mixed sexes used in the study were obtained from a cat fish farm, Department of Zoology, University of Nigeria. They were acclimatized for one week during which they were fed normal (basal) fish diet, two times daily and water was changed two times weekly. On the second week, experimental diet (basal diet + sodium propanoate) was introduced.

\section{Experimental diets preparation}

The data below shows the composition of the experimental diet (Table 1).

\section{Experimental design}

The fish juveniles were randomly assigned into 5 groups (A-E) of twenty (20) per group. The five groups were each, sub-assigned into two (2) replicates of 10 fish per replicate. Each replicate was housed in a plastic bowl containing 1520 litres of clean tap water. The treatments were as follows:

Group A: Received experimental diet containing 0\% sodium propanoate $/ 15 \mathrm{~kg}$ of feed (Control).

Group B: Received experimental diet containing 25\% sodium propanoate $/ 15 \mathrm{~kg}$ of feed.

Group C: Received experimental diet containing 50\% sodium propanoate $/ 15 \mathrm{~kg}$ of feed.

Group D: Received experimental diet containing $75 \%$ sodium propanoate $/ 15 \mathrm{~kg}$ of feed.

Group E: Received experimental diet containing 100\% sodium propanoate $/ 15 \mathrm{~kg}$ of feed.

All treatments were made two (2) times per day and lasted for eight weeks. At the end of the treatments, samples were collected for laboratory analyses.

\section{Sample collections}

Blood samples were collected via the mid ventral tail vein into sample bottles devoid of anticoagulant. The blood samples were centrifuged at 10,000 g for 10 mins and sera were harvested for biochemical analyses.

The fish were sacrificed under mild ether anaesthesia and the liver samples were collected for histopathology evaluation.

\section{Evaluation of biochemical parameters}

Estimation of lipidperoxidation (Malondialdehyde)

Lipid peroxidation was estimated by measuring spectrophotometrically, the level of the lipid peroxidation product, malondialdehyde (MDA) as described by Wallin et al. (1993).

Lipid degradation occurs forming such products as malondialdehyde (from fatty acids with three or more double bonds), ethane and pentane (from the n-terminal carbons of 3 and 6 fatty acids, respectively). MDA reacts with thiobarbituric acid to form a red or pink coloured complex which in acid solution absorbs maximally at 532 $\mathrm{nm}$.

Exctly $0.1 \mathrm{ml}$ of the serum was mixed with $0.9 \mathrm{ml}$ of $\mathrm{H}_{2} \mathrm{O}$ in a test tube. A volume of $0.5 \mathrm{ml}$ of $25 \%$ TCA (trichloroacetic acid) and $0.5 \mathrm{ml}$ of $1 \%$ TBA (thiobarbituric acid) in $0.3 \% \mathrm{NaOH}$ were also added to the mixture. The mixture was boiled for $40 \mathrm{~min}$ in a water-bath and then cooled in cold water. Then, $0.1 \mathrm{ml}$ of $20 \%$ sodium dodecyl sulfate (SDS) was added to the cooled solution and mixed properly. The absorbance was taken at $532 \mathrm{~nm}$ and $600 \mathrm{~nm}$ against a blank.

$$
\text { \%TBARS }=\left(\mathrm{A}_{532}-\mathrm{A}_{600} / 0.527 \times 0.1\right) \times 100(\mathrm{mg} / \mathrm{dl})
$$

Table 1. Experimental diet formulation with different levels of sodium propanoate (in grams per $15 \mathrm{~kg}$ diet)

\begin{tabular}{cccccc}
\hline Feed stuff & A & B & C & D & 460 \\
\hline Fish meal & 460 & 460 & 460 & 460 & 460 \\
Soybean meal & 460 & 460 & 35 & 35 \\
Wheat offal & 35 & 35 & 35 & 35 \\
White corn & 35 & 35 & 5 & 5 \\
Vitalyte & 5 & 5 & 5 & 5 \\
DCP & 5 & 5 & 50 & 5 \\
Sodium propionate & 0 & 25 & 100 & 75 \\
\hline
\end{tabular}


462

\section{Estimation of catalase activity}

The activity of catalase was assayed by the method according to Sinha (1972). Dichromate in acetic acid was reduced to chromic acetate, when heated in the presence of hydrogen peroxide with the formation of acid as an unstable intermediate. The chromic acetate formed was measured at $590 \mathrm{~nm}$. Catalase was allowed to split $\mathrm{H}_{2} \mathrm{O}_{2}$ for different periods of time. The reaction was stopped at different time intervals by the addition of dichromate acetic acid mixture and the remaining $\mathrm{H}_{2} \mathrm{O}_{2}$ was determined by measuring chromic acetate spectrophotometrically after heating the reaction mixture. The chemicals used were as follows:

1. Phosphate buffer, $0.01 \mathrm{M}, \mathrm{pH}=7$

2. Hydrogen peroxide, $0.2 \mathrm{M}$

3. Potassium dichromate, $5 \%$

4. Dichromate acetic acid reagent: Potassium dichromate and glacial acetic acid were mixed in ratio of 1:3. From this, $1 \mathrm{ml}$ was diluted again with $4 \mathrm{ml}$ of acetic acid.

\section{Procedure}

Exactly $0.1 \mathrm{ml}$ of plasma and $0.4 \mathrm{ml}$ of $\mathrm{H}_{2} \mathrm{O}_{2}$ were adde $\mathrm{d}$ to $0.9 \mathrm{ml}$ of phosphate. The reaction was stopped after 15 , 30,45 and 60 seconds by adding $2 \mathrm{ml}$ of dichromate acetic acid mixture. The tubes were kept in a boiling water bath for $10 \mathrm{~min}$ and cooled. The colour developed was read at $530 \mathrm{~nm}$. Standards in the concentration range of 20-100 umoles were processed for the test. The activity of catalase was expressed as $\mathrm{U} / \mathrm{ml}$ for plasma (U- $\mu$ moles of $\mathrm{H}_{2} \mathrm{O}_{2}$ Utilised / second).

Catalase activity $=\log \mathrm{A} / \mathrm{B} \times 0.23 / 0.00693$

$C$-reactive protein (CRP) assay

The method of Dupuy et al. (2003) was used. Exactly 450 microlitre of R1 (activation buffer) was mixed with 50 microlitre of R2 (latex reagent: uniform suspension of polystyrene latex particles coated with anti-CRP antibody) and incubated at $37^{\circ} \mathrm{C}$ for $5 \mathrm{~min}$. Thereafter, $5 \mathrm{ml}$ of serum sample were added to the above mixture and absorbance was read at wavelength $630 \mathrm{~nm}$ after $10 \mathrm{sec}$ as A1 and after 2 mins as A2.

Similarly, the CRP standard (calibrator) was processed in the same manner as the samples.

Concentration of CRP in the sample = change in absorbance $(\mathrm{A})$ of the sample $\times$ concentration of standard /change in absorbance (A) of standard.

Where change in $\mathrm{A}=(\mathrm{A} 2-\mathrm{A} 1)$

Concentration of the standard $=2 \mathrm{mg} / \mathrm{dl}$ (A lyophilized preparation of serum equivalent to the stated amount of CRP on a $\mathrm{mg} / \mathrm{dl}$ basis).

\section{Histopathology examination}

The histological examination of the liver tissues of the fish was done using the method of Drury et al. (1967).

\section{A. Fixation and washing}

Formalin (10\%) was used as fixative and for the purpose of preservation. A thin section of the tissue (about 1 to 2 $\mathrm{cm}$ in diameter) was trimmed with a sharp razor blade. The small pieces of the tissue were placed in the $10 \%$ formalin, the container was shaken gently several times to make sure that the fluid had reached all surfaces and that pieces were not sticking to the bottom. This was then incubated at 25
${ }^{\circ} \mathrm{C}$ for $24 \mathrm{~h}$, to allow proper fixing. The fixed tissue pieces were washed with running water for $24 \mathrm{~h}$ to free them from excess fixatives.

\section{B. Debydration}

Water was removed from the tissue before embedding the tissue in paraffin. The dehydration was achieved by immersing the thin sections of the tissue in automatic tissue processor containing 12 jars. The first three jars contained 70, 90 and $95 \%$ absolute alcohol respectively. This was done to remove the water content in the tissues. The absolute alcohol reduced the shrinking that occurred in the tissue. The time for each step was $30 \mathrm{~min}$. A second change of absolute alcohol was included to ensure complete removal of water. This was achieved in the second three jars of the automatic tissue processor.

\section{Clearing}

Solutions of xylene were used for clearing the tissue sections. This step was achieved in the third three jars of the automatic tissue processor. Because the alcohol (ethanol) used for dehydration would not dissolve or mix with molten paraffin, the tissue was immersed in xylene solution which was miscible with both alcohol and paraffin before infiltration could take place. Clearing was done to remove opacity from dehydrated tissue. A period of 15 min was allowed to elapse before the tissue was removed from the solution for infiltration with paraffin.

D. Infiltration with paraffin

Paraffin wax at 50 to $52{ }^{\circ} \mathrm{C}$ was used to infiltrate the tissue. The tissue was transferred directly from the clearer to a bath containing melted paraffin. After 30-60 min incubation in the first bath, the tissue was then removed to a fresh dish of paraffin contained in the fourth three jars of the automatic tissue processor for a similar length of time.

\section{E. Embedding (blocking) with paraffin}

As soon as the tissue was thoroughly infiltrated with paraffin, it was allowed to solidify around and within the tissue.

\section{F. Paraffin sectioning}

The embedded blocks were trimmed into squares and fixed in the microtome for sectioning after which the sections were floated on a water bath.

\section{G. Mounting}

Glass slides were thoroughly cleaned and a thin smear of albumen fixative was made on the slides. The albumenized slide was used to collect the required section from the rest of the ribbon in the water. The section on the glass slide was kept moist before staining.

\section{H. Staining with haematoxylin}

The slides were passed through a series of jars containing alcohols of decreasing strength and various staining solutions.

\section{Microscopic observation of slide}

The slides prepared were mounted on a photomicroscope and viewed at different magnifications. A photograph of each of the slides was taken.

\section{Statistical analysis}

Data on biochemical parameters were analyzed with One-way Analysis of Variance (ANOVA). Variant means were separated with Duncan'sMultiple Range post hoc test. Significance was accepted at probability level less than 0.05 . 


\section{Results}

There were no significant differences $(p>0.05)$ in plasma malondialdehyde values of all the groups across the treatment period. The serum catalase activities of groups D and $\mathrm{E}$ fishes were significantly $(\mathrm{p}<0.05)$ higher than their group A (normal, control) counterpart, while the serum Creactive protein levels of the control (Group A) and those that received the lowest incorporation of sodium propanoate (Group B) fishes were significantly higher than those of groups C, D and E (Table 2 and Figs 1-5).

Table 2. Effect of sodium propanoate on some oxidative stress parameters of Clarias gariepinus (African cat fish)

\begin{tabular}{cccc}
\hline Group/Parameters & Malondialdehyde $(\mathrm{mg} / \mathrm{ml})$ & Catalase $(\mathrm{IU} / \mathrm{L})$ & C-reactive protein $(\mathrm{mg} / \mathrm{dl})$ \\
\hline A & $2.04 \pm 0.19^{\mathrm{a}}$ & $3.58 \pm 0.53^{\mathrm{a}}$ & $3.76 \pm 0.08^{\mathrm{b}}$ \\
B & $1.76 \pm 0.32^{\mathrm{a}}$ & $3.77 \pm 0.62^{\mathrm{a}}$ & $3.73 \pm 0.11^{\mathrm{b}}$ \\
C & $1.74 \pm 0.08^{\mathrm{a}}$ & $4.83 \pm 0.29^{\mathrm{ab}}$ & $2.95 \pm 0.09^{\mathrm{a}}$ \\
D & $1.41 \pm 0.25^{\mathrm{a}}$ & $5.54 \pm 0.16^{\mathrm{b}}$ & $2.65 \pm 0.24^{\mathrm{a}}$ \\
E & $1.33 \pm 0.16^{\mathrm{a}}$ & $5.29 \pm 0.33^{\mathrm{b}}$ & $2.53 \pm 0.23^{\mathrm{a}}$ \\
\hline
\end{tabular}

Different superscripts along the same column (across groups) indicate significant differences at $\mathrm{p}<0.05$

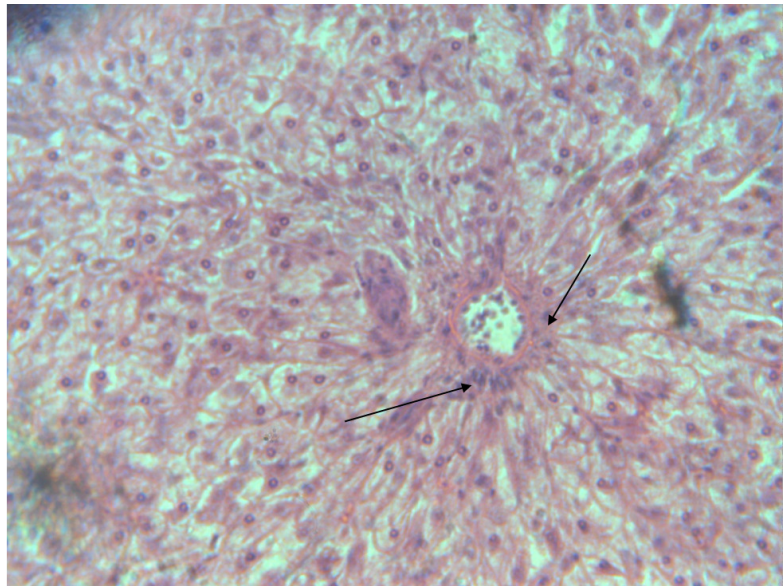

Fig. 1. Group A H\&E X400 LIVER showing mild localized periportal infiltration by inflammatory cells (arrows)

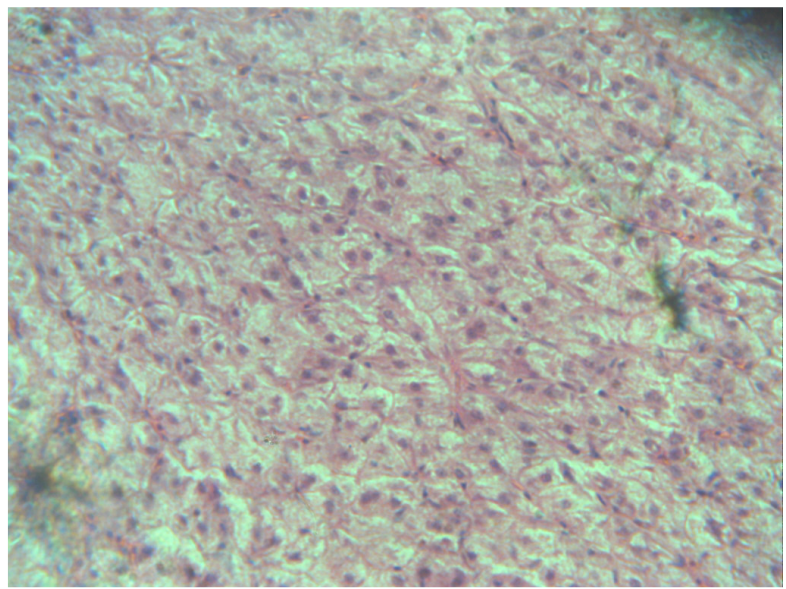

Fig. 3. Group C H\&E X 200 LIVER showing normal liver architecture

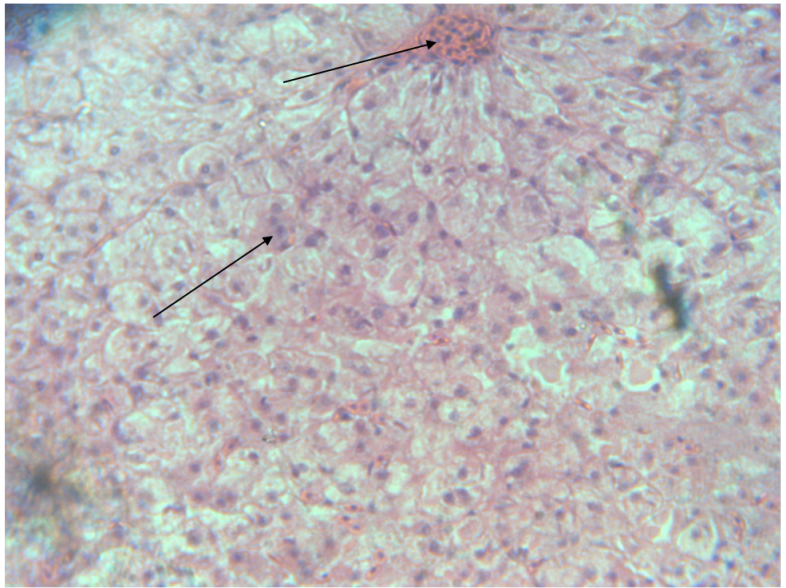

Fig. 2. Group B H\&E X400 LIVER showing normal hepatocytes arranged in cords with central vein filled with red blood cells

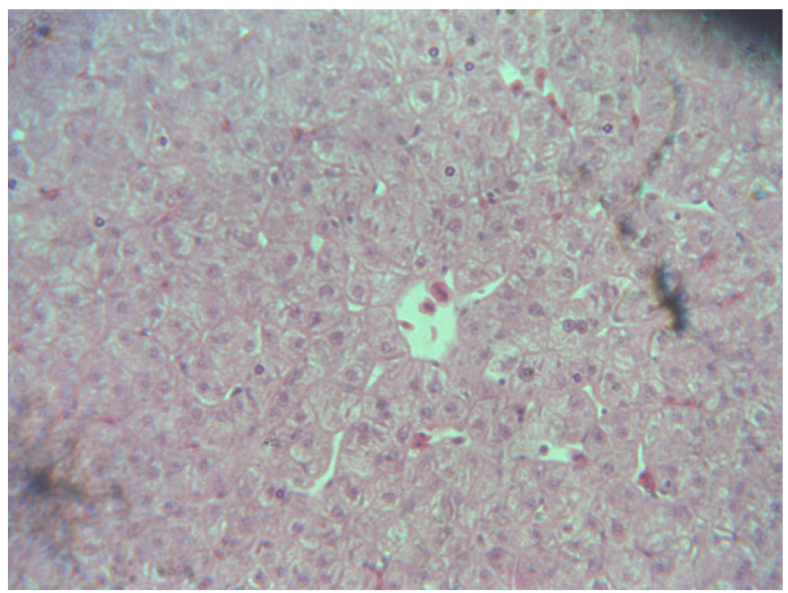

Fig. 4. Group D H\&E X400 LIVER normal hepatocytes showing central vein 


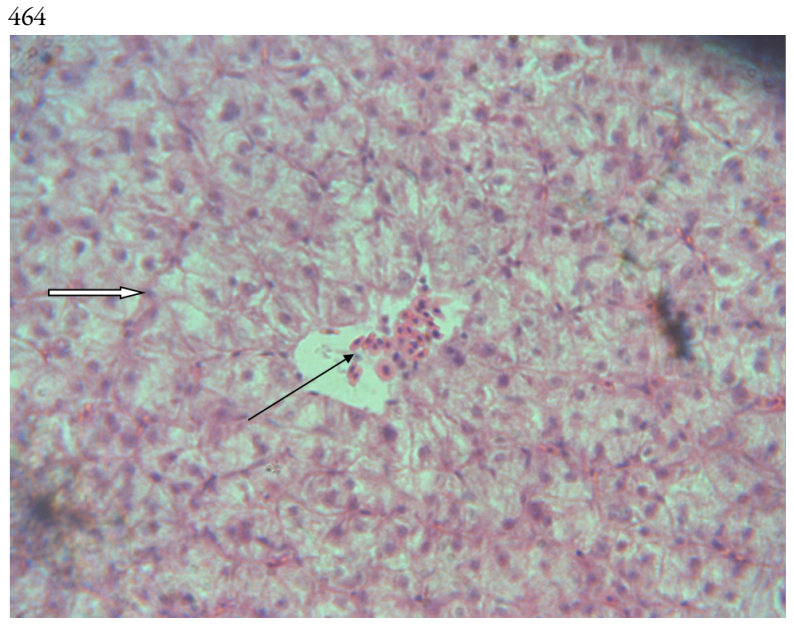

Fig. 5. Group E H\&E X400 LIVER. Normal liver showing central vein with red blood cells inside (small black arrow), hepatocytes (white arrow)

\section{Discussion}

The present study investigated the effects of sodium propanoate-preserved fish feed on a few biochemical parameters and on the hepatic histology.

Upon eight weeks administration of sodium propanoate in feeds, results indicate that the catalase activities of the group that received the highest concentration of sodium propanoate in feed was significantly higher than that of the control group which received basal diet (Table 2). This indicates that inclusion of sodium propanoate enhanced the activity of the antioxidant enzyme. Catalase plays vital role in amelioration of oxidative stress. Catalase causes the decomposition of hydrogen peroxide which is generated in the course of tissue metabolism to water and molecular oxygen (Chelikaniet al., 2004). Antioxidant properties of sodium propanoate had earlier been reported in Zebra fish in a study conducted by Safari et al. (2016).

The serum levels of C-reactive protein of the fish group that received the highest incorporation of sodium propanoate were significantly lower than that of the normal control group (Table 1). C-reactive protein is an acute phase protein that indicates the levels of inflammation (Young et al., 1999. The decreases in the serum levels of C-reactive protein in the group that received feed with sodium propanoate indicates that sodium propanoate may have anti-inflammatory properties. Literature search revealed that sodium propanoate is an anti-fungus (Brock and Buckel, 2004). Tedelindet al. (2007) also submitted the anti-inflammatory properties of short chain fatty acids such as propionate.

The finding of insignificant changes in the plasma malondialdehyde levels of control group when compared with the treated groups (groups that received sodium propanoate -incorporated feeds) indicate that the sodium propanoate may not have interfered with lipid peroxidation of the fish (Table 1). Malondialdehyde is a stable product of lipid peroxidation that is useful in assessing the magnitude of lipid peroxidation in the cell membranes (Urso and Clarkson, 2003; Grotto et al., 2009).
The histopathology results suggest that the dietary sodium propanoate may have protected the liver against any inflammatory or degenerative conditions. The photomicrograph of the liver indicates that the fish groups that received sodium propanoate-incorporated feed showed normal hepatocytes and hepatic architecture (Figs. 2-5) when compared to that of the normal control (Fig. 1) which showed mild degenerative lesion. It can be suggested that the finding of such lesion in the liver of fish fed normal basal diet may be indicative that the feed could have deteriorated since there was no preservative incorporated. Absence of preservative such as sodium propionate predisposes feeds to becoming mouldy (Brock and Buckel, 2004). Mouldy feed could be potentially harmful to the liver, especially if aflatoxin is involved. Aflatoxins particularly have been shown to be involved in oxidative stress and inflammatory processes and could cause hepatocellular disorders (Qin et al., 2016). Literature search also showed that aflatoxin is toxic in channel cat fish and tilapia (Chavez-Sanchezet al., 1994).

\section{Conclusions}

It was concluded that preservation of Clarias gariepinus feed with varying levels of sodium propanoate produced desirable effects. Groups that received feeds incorporated with sodium propanoate showed normal liver histology and improved antioxidant status, with no inflammation when compared to the fish group that did not receive the sodium propanoate-incorporated feed. Apart from being used as preservative, sodium propanoate could also positively add to the value of feed.

\section{References}

Aba PE, Asuzu IU (2015). Effects of administration of methanol root bark extract of Cussonia arborea on serum biochemical markers of liver damage and histo-morphology of liver of alloxan-induced diabetic rats. British Journal of Pharmaceutical Research 8(6):1-10.

Aba PE, Okenwa-Ani CP (2015). Biochemical effects of methanolic extracts of Vernonia amygdalina and Gongronema latifolia on alloxan-induced diabetic rats. British Journal of Pharmaceutical Research 9(2):1-10.

BallouSP (1992). C-reactive protein and the acute phase response. Advances in Internal Medicine 37:313-316.

Brock M, Buckel W (2004). On the mechanism of action of the antifungal agent propionate: Propionyl-CoA inhibits glucose metabolism in Aspergillus nidulans. European Journal of Biochemistry 271(15):32273241.

Chavez-Sanchez MC, Palacios CM, Moreno IO (1994). Pathological effects offeedingyoung Oreochromis niloticus diets supplemented with different levels of aflatoxin B1. Aquaculture 127(1):49-60.

Chelikani P, Fita L, Loewen PC (2004). Diversity of structures and properties among catalases. Cellular and Molecular Life Sciences 61(2):192-208.

da Silva BC, Vieira FDN, Mouriño JLP, Bolivar N, Seiffert WQ (2014). Butyrate and propionate improve the growth performance of Litopenaeusvannamei. Aquaculture Research 47(2):612-623. 
Drury RA, Wallington A, Cameroun SR (1967). Histological techniques. Oxford University Press, New York pp 1-420.

Dupuy AM, Badiou S, Descomps B, Cristol JP (2003). Immunoturbidimetric determination of $\mathrm{C}$-reactive protein $(\mathrm{CRP})$ and high sensitivity CRP on heparin plasma. Comparison with serum determination. Clinical Chemistry and Laboratory Medicine 41(7):948-949.

Grotto D, Maria LS, ValentiniJ, Paniz C, Schmitt G, Garcia, et al., Farina M (2009). Importance of the lipid peroxidation biomarkers and methodological aspects for malondialdehyde quantification. Quimica Nova 32(1):169-174.

Okorie-Kanu CO, Unkalamba NJ (2016). Haematological and blood biochemistry values of cultured Heterobranchus longifillis in Umudike, AbiaState, Nigeria. Animal Research International 11(2):1987-1993.

Qin H, Li H, Zhou X, Peng C, et al., Wang M (2016). Effect of superoxide and inflammatory factor on Aflatoxin B1 triggered hepatocellular carcinoma. American Journal of Translational Research 8(9):4003.

Safari R, Hoseinifar SH, Kavandi M (2016). Modulation of antioxidant defense and immune response in Zebra Fish (Danio rerio) using dietary sodium propionate. Fish Physiology and Biochemistry 42(6):17331739.
Sinha AK (1972). Colorimetric assay of catalase. Analytical Biochemistry $47(2): 389-394$.

Subramanian D, Jang YH, Kim DH, Kang BJ, Heo MS (2013). Dietary effect of Rubus coreanus ethanolic extract on immune gene expression in white leg shrimp, Penaeus vannamei. Fish \& Shellfish Immunology 35(3):808-814.

Tedelind S, Westberg F, Kjerrulf M, Vidal A (2007). Anti-inflammatory properties of short chain fatty acids acetate and propionate: A study with relevance to inflammatory bowel disease. World Journal of Gastroenterology 13(20):2826.

Urso ML, Clarkson PM (2003). Oxidative stress, exercise and antioxidant supplementation. Toxicology 189(1-2):41-54.

Wallin B, Rosengren B, Shertyer HG, Camejo G (1993). Lipoprotein oxidation and measurement of thiobarbituric acid reacting substances formation in a single microfilter plate: its use for evaluation of antioxidants. Analytical Biochemistry 208(1):10-15.

Young B, Gleeson M, Cripps AW (1999). C-reactive protein: a critical review. Pathology 23(2):118-124. 